\title{
Prehospital cooling in cardiac arrest - the next frontier? Eldar Søreide
}

\author{
Address: Department of Anaesthesia and Intensive Care, Stavanger University Hospital, Stavanger, Norway \\ Email: Eldar Søreide - soed@sus.no
}

Published: 12 October 2009

Scandinavian Journal of Trauma, Resuscitation and Emergency Medicine 2009, 17:54 doi:I0.II86/1757-724I-I7-54

This article is available from: http://www.sjtrem.com/content/17/I/54

(C) 2009 Søreide; licensee BioMed Central Ltd.

This is an Open Access article distributed under the terms of the Creative Commons Attribution License (http://creativecommons.org/licenses/by/2.0), which permits unrestricted use, distribution, and reproduction in any medium, provided the original work is properly cited.
Received: 14 September 2009 Accepted: 12 October 2009

\section{Commentary}

Therapeutic hypothermia (TH) in unconscious survivors of out-of-hospital cardiac arrest (OHCA) is now a welldocumented part of post-resuscitation care $[1,2]$. Implementation of TH into daily clinical practice has been far more successful in the Scandinavian countries than in the rest of the world $[3,4]$. Still, many questions remain unanswered:

- Is there a better, safer and more rapid way of cooling these patients?

- Does rapid cooling necessarily mean prehospital cooling?

- And, will rapid prehospital cooling translate into higher survival rates and better neurological outcomes?

In this issue of the Journal, two international research groups within this exciting and rapidly progressing field of critical care medicine have reviewed the present knowledge on prehospital cooling in OHCA $[5,6]$. Behringer et al [5] give an excellent overview on what is known about prehospital preservative and resuscitative hypothermia. Their main focus is on resuscitative hypothermia - meaning cooling initiated after return of spontaneous circula- tion (ROSC). Both non-invasive cooling pads and IV. infusion of ice-cold fluids have been shown to be feasible alternatives in the prehospital environment, securing earlier induction of the cooling process. What is lacking is convincing human data on improved clinical outcomes. Kämäräinen et al [6] come to the same conclusion. In their review they also mentioned a specially designed cooling cap as a possible method of (selective) brain cooling. They also review the present human data on prehospital intra-arrest cooling. After much promising animal data, little more than feasibility and safety data has been published in humans. However, this may all change in the next months to come.

The Australian trial on prehospital cooling versus in-hospital cooling in OHCA survivors (RICH-trial) has been presented at an international medical meeting. The trial now has been broadened to include intra-arrest cooling as well (Stephen Bernard, personal communication). The recent $3^{\text {rd }}$ International Hypothermia Symposium http:// www.hypo2009.com in Lund, Sweden also presented break-through research in the field, one being intra-arrest trans-nasal cooling with a highly evaporative perfluorocarbon spray. The technique has been shown to improve ROSC rates and secure very rapid brain cooling in animal studies [7]. Preliminary Swedish results from a multi-centre European trial indicate that intra-arrest trans-nasal 


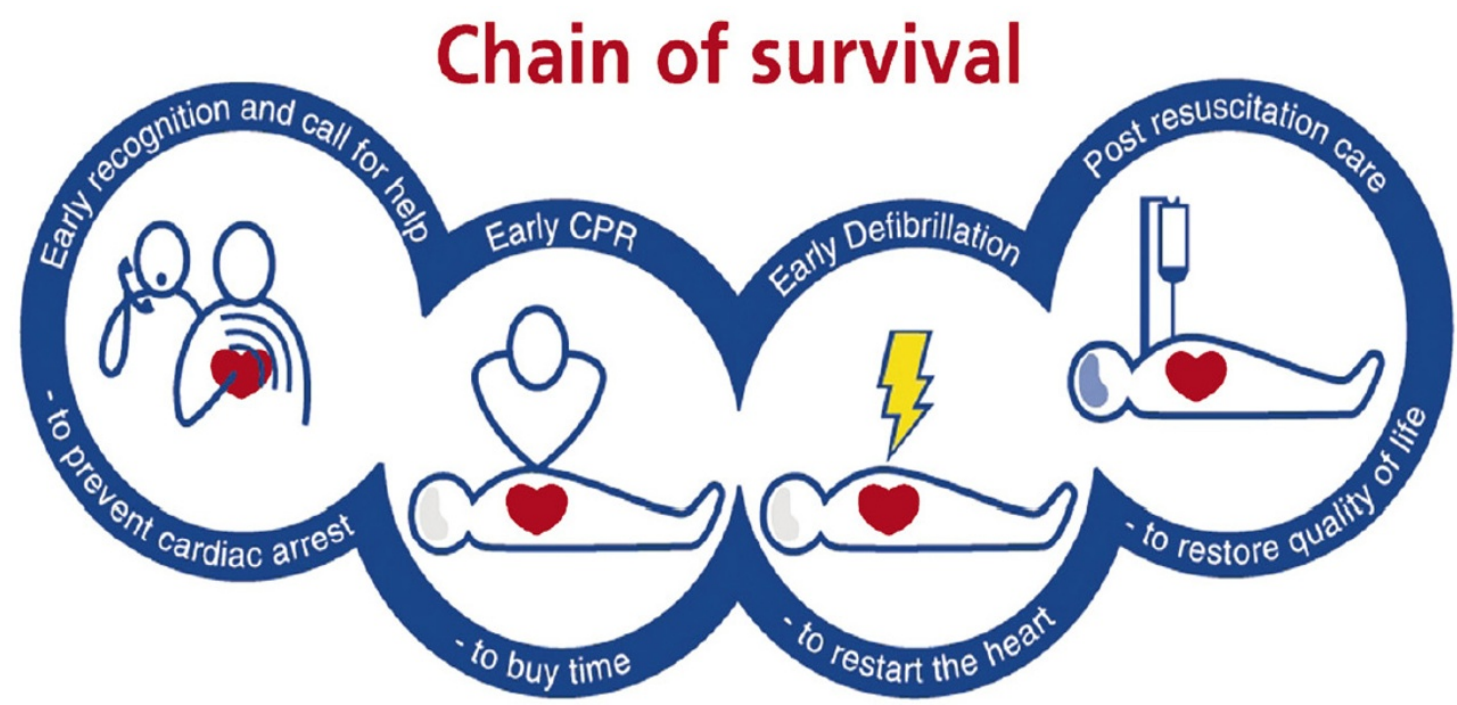

Figure I

The ERC 2005 Chain of Survival. From: Jerry Nolan, Jasmeet Soar, and Harald Eikeland. Resuscitation 2006, 7I, 270--27I

cooling using this commercial available device may improve ROSC rates and survival also in humans. However, the promising results have yet to be published in peer-reviewed journals. We therefore need to be cautious before jumping to conclusions affecting our clinical practice.

One concern raised in the current reviews $[5,6]$ is the lack of on-going hospital cooling in patients brought to hospital after prehospital cooling had been commenced. Some studies actually reported active hospital warming of patients cooled during ambulance transport. This is probably worse than no cooling at all. This should act as a reminder to us all that for the Chain of Survival (Figure 1) to get stronger, clinicians inside and outside hospitals must work together. Together, we should decide not only how and when to cool, but also who to cool. It does not make sense anymore to limit cooling to VF cardiac arrests only $[1,2,8]$. We cool the brain because it suffers from a combination of anoxic and re-perfusion injury, not because of a specific heart rhythm. If you decide to treat unconscious survivors of OHCA actively in the ICU, TH should be part of standard care. Whether you should move the cooling into ambulances or the homes of cardiac arrest victims is another discussion not yet settled. In order to decide what your future treatment strategy should be, a very good starting point is to read the two present reviews on prehospital cooling $[5,6]$.

\section{References}

I. Polderman $\mathrm{KH}$ : Induced hypothermia and fever control for prevention and treatment of neurological injuries. Lancet 2008, 371:1955-69.

2. Nolan JP, Neumar RW, Adrie C, Aibiki M, Berg RA, Bottiger BW, Callaway C, Clark RS, Geocadin RG, Jauch EC, Kern KB, Laurent I, Long- streth WT, Merchant RM, Morley P, Morrison LJ, Nadkarni V, Peberdy MA, Rivers EP, Rodriguez-Nunez A, Sellke FW, Spaulding C, Sunde K, Hoek TV: Post-cardiac arrest syndrome: epidemiology, pathophysiology, treatment, and prognostication. A Scientific Statement from the International Liaison Committee on Resuscitation; the American Heart Association Emergency Cardiovascular Care Committee; the Council on Cardiovascular Surgery and Anesthesia; the Council on Cardiopulmonary, Perioperative, and Critical Care; the Council on Clinical Cardiology; the Council on Stroke. Resuscitation 2008, 79:350-79.

3. Soreide E, Sunde K: Therapeutic hypothermia after out-of hospital cardiac arrest: how to secure worldwide implementation. Curr Opin Anaesthesiol 2008, $21: 209-15$.

4. Busch M, Soreide E: Prognostication after out-of-hospital cardiac arrest, a clinical survey. Scand J Trauma Resusc Emerg Med 2008, 16:9.

5. Behringer W, Arrich J, Holzer M, Sterz F: Out-of-hospital therapeutic hypothermia in cardiac arrest victims. Scand J Trauma Resusc Emerg Med 2009, 17:52.

6. Kämäräinen A, Hoppu S, Silfvast T, Virkkunen I: Prehospital therapeutic hypothermia after cardiac arrest - from current concepts to a future standard. Scand J Trauma Resusc Emerg Med 2009, 17:53.

7. Tsai MS, Barbut D, Tang W, Wang H, Guan J, Wang T, Sun S, Inderbitzen B, Weil MH: Rapid head cooling initiated coincident with cardiopulmonary resuscitation improves success of defibrillation and post-resuscitation myocardial function in a porcine model of prolonged cardiac arrest. J Am Coll Cardiol 2008, 5I:1988-90.

8. Nielsen N, Hovdenes J, Nilsson F, Rubertsson S, Stammet P, Sunde K, Valsson F, Wanscher M, Friberg H: Outcome, timing and adverse events in therapeutic hypothermia after out-of-hospital cardiac arrest. Acta Anaesthesiol Scand 2009, 53:926-34. 